\title{
Sea Turtle Conservation: Priorities for Environmental Education Efforts ${ }^{1}$
}

\author{
Jessica E. Swindall, Holly K. Ober, Margaret M. Lamont, and Raymond R. Carthy²
}

Five species of sea turtles occur in Florida, and all are in danger of extinction. Many of the reasons these turtles are declining are a result of people's actions on beaches and in shallow coastal waters (Figure 1). Therefore, environmental education programs are needed to increase awareness and appreciation for sea turtles, and to teach about the potential harmful impacts human behaviors can have on these animals. Such efforts should share ideas on how people can help sea turtles and how they can reduce harm.

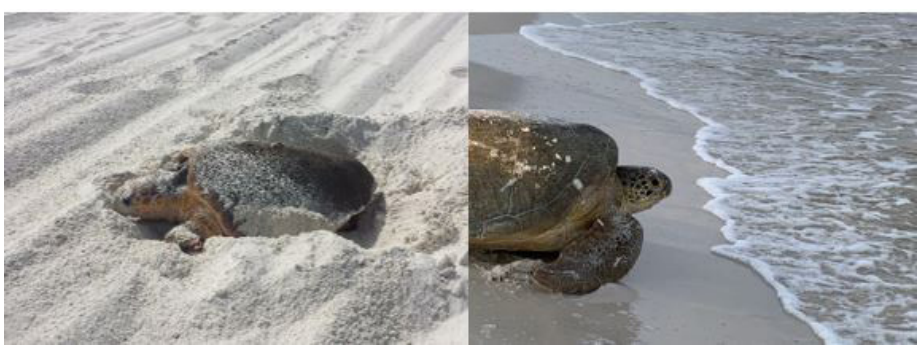

Figure 1. Sea turtles, such as this loggerhead (left) and green (right), are vulnerable to human disturbance when they come ashore to nest on beaches.

Credits: Jessica Swindall (left), Margaret Lamont (right).

Environmental education strategies are most effective when educators have a thorough understanding of what topics are frequently misunderstood, along with awareness of what helpful or harmful activities are commonly occurring. A recent survey in four coastal counties in northwest Florida (Walton, Bay, Gulf, and Franklin Counties) assessed people's understanding of sea turtles and their habitat needs, evaluated their understanding of how humans impact sea turtles, and asked how often they engage in behaviors helpful or harmful to sea turtles. The results of this survey provided insight into which topics could be addressed during environmental education efforts on sea turtles and specific messages most important for sea turtle conservation efforts.

\section{Topics to Address in Sea Turtle Environmental Education Programs \\ Public Knowledge of Basic Ecology of Sea Turtles}

The general public in coastal counties of north Florida generally has limited understanding of basic ecological concepts regarding sea turtles.

The topics people know the least about are:

- The role of dunes in influencing sea turtle behavior (Dunes or other tall objects that block onshore artificial lights prompt turtles to crawl away from the darkness inland and towards the lighter horizon over the open ocean.)

1. This document is WEC420, one of a series of the Department of Wildlife Ecology and Conservation, UF/IFAS Extension. Original publication date February 2020. Visit the EDIS website at https://edis.ifas.ufl.edu for the currently supported version of this publication.

2. Jessica E. Swindall, former graduate research assistant, Department of Wildlife Ecology and Conservation; Holly K. Ober, associate professor and Extension specialist, UF/IFAS North Florida Research and Education Center; Margaret M. Lamont, biologist, US Geological Survey, Wetland and Aquatic Research Center; and Raymond R. Carthy, assistant unit leader, US Geological Survey-Florida Cooperative Fish \& Wildlife Research Unit; UF/IFAS Extension, Gainesville, FL 32611.

The Institute of Food and Agricultural Sciences (IFAS) is an Equal Opportunity Institution authorized to provide research, educational information and other services

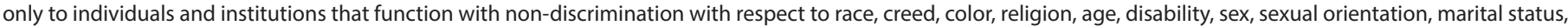

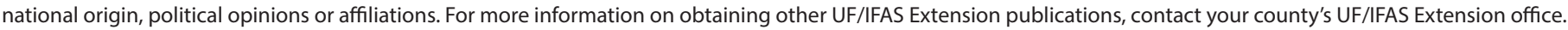
U.S. Department of Agriculture, UF/IFAS Extension Service, University of Florida, IFAS, Florida A \& M University Cooperative Extension Program, and Boards of County Commissioners Cooperating. Nick T. Place, dean for UF/IFAS Extension. 
- How much stored energy newly hatched sea turtles have (Upon emerging from their nest, hatchlings have enough energy to crawl to the water and swim for up to 15 days in the Gulf of Mexico.)

- Where loggerhead sea turtles spend the early stage of their lives (These turtles spend several years drifting passively in the open ocean before they move into coastal waters and estuaries.)

- What items are important food sources for the most common sea turtle species in Florida (Shellfish and other hard-shelled benthic invertebrates such as horseshoe crabs, whelks, and urchins are essential for loggerheads and Kemp's ridley turtles; vegetation such as sea grass is eaten by greens; and jellyfish are eaten by leatherbacks.)

People are slightly more informed about the following ecological concepts:

- Sea turtle lifespans (The average sea turtle lifespan is over 60 years.)

- Where on the beach sea turtles nest (Nesting can occur anywhere from the water's edge to the dunes.)

People are most knowledgeable about the following topics:

- The location of sea turtle foraging grounds (Many turtles forage in seagrass beds.)

- The number of sea turtle species in Florida (Five turtle species can be found nesting in Florida.)

\section{Public Knowledge of Human Impacts to Sea Turtles}

The general public in coastal counties of north Florida generally have slightly better understanding of how human behavior affects sea turtles than they do of basic turtle biology.

The topics people know the least about are:

- The negative effects of seawalls on sea turtles (Seawalls are harmful to turtles because they prevent adult females from crawling onto beaches to nest, and they disrupt the natural sand erosion and accretion cycles that renew beaches required for nesting.)

- Which types of light bulbs cause the least harm to sea turtles (Sea turtles are least likely to be disoriented by lights with long wavelengths: these are bulbs that emit light that appears red or amber in color.)

- The ways boating activities can harm sea turtle foraging areas (Driving motorboats with propellers in shallow water can gouge seagrass beds and create trenches in seagrass meadows, causing long-term harm to turtle foraging grounds.)

People are slightly more informed about the following concepts:

- The harm caused to sea turtles by driving vehicles on beaches (Ruts in the sand created by vehicles driven on beaches can disorient hatchlings moving from their nest to the sea. This can result in death if hatchlings become entrained in the ruts and use too much energy crawling in the wrong direction.)

- The type of harm caused by various types of fishing gear (Entanglement in monofilament fishing line or ingestion of a plastic lure are even more harmful than a fishing hook in a turtle's flipper.)

People are most knowledgeable about the following issues:

- The most appropriate agency to notify about entanglement of sea turtles in fishing gear in Florida (The Florida Fish \& Wildlife Conservation Commission should be notified immediately when a sea turtle is found to be impacted by any sort of net or hook.)

- Harm potentially caused to sea turtles by beach recreation equipment (Chairs or tents left on the beach overnight can cause turtles to become entangled or disoriented as they move between nests and the ocean.)

- Timing fertilizer use to reduce pollution through run-off (Avoid fertilizing lawns prior to heavy rainfall to reduce pollution in nearby water bodies.)

\section{Human Behaviors that Impact Sea Turtles}

Regardless of knowledge, the behaviors people engage in are a true measure of the impact people have on the environment. The general public in coastal counties of north Florida generally choose environmentally friendly actions.

The turtle-friendly behaviors most common in coastal areas are:

- Shading windows at night (Curtains, blinds, shades, and window tinting can reduce the amount of light pollution outdoors that might disorient turtles.)

- Observing sea turtles at the recommended distance when on the beach or in the water (According to the National Oceanic and Atmospheric Administration [NOAA], the minimum distance from which sea turtles should be viewed in the water or on the beach is 50 yards.)

- Never leaving a fishing line unattended (Sea turtles can become entangled in unattended fishing lines.) 
- Never driving on the beach (Sea turtle hatchlings can become disoriented by ruts created by tires of vehicles driven in the sand, wasting their limited energy reserves as they crawl to the ocean.)

Environmentally friendly behaviors adopted by moderate numbers of people in coastal areas are:

- Always securing trash in enclosures (Trash on beaches or in nearshore waters can entangle sea turtles, so should always be placed in trash cans. Additionally, stashing trash in cans with lids can reduce food sources that might attract raccoons, a predator of sea turtle hatchlings and eggs.)

- Never or rarely fertilizing their lawns (Excess fertilizer can pollute nearshore waters, harming sea turtles or their food. Fertilizer should not be applied prior to heavy rainfall events.)

Environmentally friendly behaviors that are uncommon in coastal areas are:

- Using designated dune walkovers or access points to get to the beach (Walking through the sand dunes should be avoided because it can cause erosion, reducing the height of the dunes that is needed to reduce lighting disturbance to guide turtles away from the land and towards the sea at night.)

- Using no exterior lighting after sunset (The longer outdoor lights are left on during turtle nesting season [May-October in the Florida Panhandle], the greater the likelihood sea turtles will be disoriented and either not get to the ocean or arrive with dangerously low energy reserves.)

- Using proper wildlife-safe bulbs in exterior lighting (Bulbs that provide long-wavelength light [greater than $560 \mathrm{~nm}$, appearing red, orange, or amber in color] are less likely to disorient turtles than bulbs producing light of other colors.)

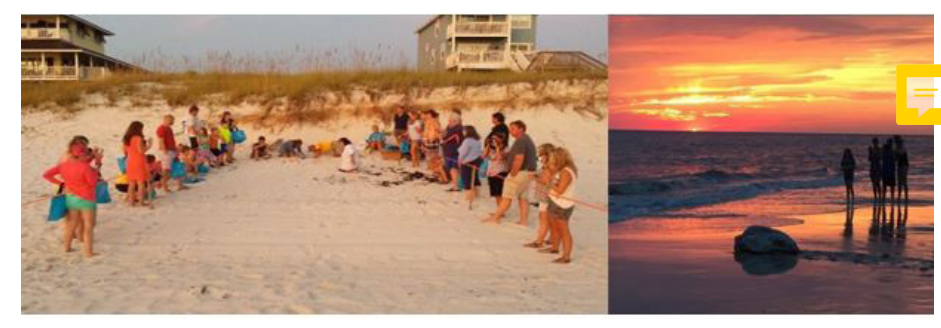

Figure 2. Nesting sea turtles provide opportunities to educate the public. According to the National Oceanic and Atmospheric Administration (NOAA), the minimum distance from which sea turtles should be viewed is 50 yards.

Credits: Jessica Swindall (left), Ximena Zornosa (right)

\section{Concluding Recommendations}

Florida is a hotspot for sea turtle activity, representing one of the most important nesting sites for loggerhead turtles in the world. The actions that residents and tourists take on the beach and in the water can have severe negative impacts on sea turtles. Simple behavioral modifications, such as keeping a safe distance from turtles nesting or hatching on the beach to prevent unnecessary energy depletion (Figure 2), can increase the likelihood of successful sea turtle reproduction, ensuring these fascinating animals are present for future generations to enjoy.

By carefully designing environmental education programs, we can increase public awareness of the most serious threats people pose to sea turtles (Table 1). The future of our sea turtles can be bright if we work to encourage conservation of these special animals.

\section{Additional Information}

Florida Fish and Wildlife Conservation Commission. 2019a. Sea Turtle Education and Information. http://www. myfwc.com/education/wildlife/sea-turtle/

Florida Fish and Wildlife Conservation Commission. 2019b. Marine Turtle Protection. http://myfwc.com/ wildlifehabitats/managed/sea-turtles/protection/

Florida Fish and Wildlife Conservation Commission. 2019c. Marine Turtles and Lights. http://myfwc.com/ wildlifehabitats/managed/sea-turtles/lighting/

Florida Fish and Wildlife Conservation Commission. 2019d. How Can I Help?. http://myfwc.com/ wildlifehabitats/managed/sea-turtles/how-to-help/

National Oceanic and Atmospheric Administration. 2019. Sea Turtles. http://www.nmfs.noaa.gov/pr/species/turtles/

Sea Turtle Conservancy. 2019. Educa-

tional Initiatives. https://conserveturtles.org/

stc-programs-educational-initiatives/

Swindall, J. E., H. K. Ober, M. M. Lamont, and R. R. Carthy. 2019a. "Informing Sea Turtle Outreach Efforts to Maximize Effectiveness." Wildlife Society Bulletin 43: 436-446.

Swindall, J. E., H. K. Ober, M. M. Lamont, and R. R. Carthy. 2019b. Sea Turtle Conservation: 10 Ways You Can Help. WEC421. Gainesville: University of Florida Institute of Food and Agricultural Sciences. https://edis.ifas.ufl.edu/ uw466

US Fish and Wildlife Service. 2019. General Sea Turtle Information. http://www.fws.gov/northflorida/SeaTurtles/ seaturtle-info.htm 
Table 1. What people should know and do in three locations where they could impact sea turtles.

\begin{tabular}{|c|c|c|}
\hline Location & Basic Ecological Concepts & Human Impacts \\
\hline In the Water & $\begin{array}{l}\text { Seagrass beds are important foraging } \\
\text { areas for sea turtles. } \\
\text { Sea turtles are long-lived: their lifespans } \\
\text { often exceed } 60 \text { years. } \\
\text { Important food sources for sea turtles } \\
\text { vary by species, and include plants, } \\
\text { shellfish, and jellyfish. } \\
\text { Sea turtles spend the early part of their } \\
\text { lives drifting and following currents out } \\
\text { at sea. }\end{array}$ & $\begin{array}{l}\text { FWC is the best agency to notify about a sea turtle entangled in fishing } \\
\text { gear. } \\
\text { Consumption of fishing lures and hooks, and entanglement in } \\
\text { monofilament are the most harmful effects of sportfishing on sea turtles. } \\
\text { Shading seagrass beds with docks and bridges and damaging seagrass by } \\
\text { creating trenches with boat propellers is harmful to sea turtles. } \\
\text { Sea turtles should be observed no closer than } 50 \text { yards when boating or } \\
\text { jet-skiing. } \\
\text { Fishing lines left unattended can harm sea turtles. }\end{array}$ \\
\hline On the Beach & $\begin{array}{l}\text { Sea turtles use dunes for orientation } \\
\text { while on land. } \\
\text { Sea turtles can nest anywhere on the } \\
\text { beach from the waterline to the dunes. } \\
\text { Five sea turtle species nest on beaches in } \\
\text { Florida. }\end{array}$ & $\begin{array}{l}\text { Recreational beach equipment left out overnight can harm sea turtles } \\
\text { nesting on the beach. } \\
\text { Walking across sand dunes can harm sea turtles by destroying important } \\
\text { habitat that they use for orientation and nesting. } \\
\text { Beach driving harms sea turtles by creating tire ruts that impede } \\
\text { hatchlings trying to crawl to the ocean. } \\
\text { Seawalls prevent sea turtles from accessing the beach to lay eggs. } \\
\text { Sea turtles should be observed from no closer than } 50 \text { yards when on the } \\
\text { beach. }\end{array}$ \\
\hline At Residence & $\begin{array}{l}\text { White, blue, and green light colors } \\
\text { negatively affect sea turtles; red, amber, } \\
\text { and orange light colors have less impact. }\end{array}$ & $\begin{array}{l}\text { Long-wavelength ( } 560 \mathrm{~nm} \text { or longer, appearing red, amber, or orange) } \\
\text { lights oriented downward are the best options when outdoor lighting is } \\
\text { necessary. } \\
\text { Fertilizer should not be applied prior to rain storms to reduce pollution of } \\
\text { waters from runoff. } \\
\text { Native plants should be used instead of non-native ornamentals adapted } \\
\text { for other climates. This can reduce fertilization and irrigation. } \\
\text { Residential trash should be secured indoors or in animal-proof trash } \\
\text { containers or enclosures so that it does not get into the ocean where it } \\
\text { might be consumed by turtles, and so that it does not attract sea turtle } \\
\text { predators such as raccoons. }\end{array}$ \\
\hline
\end{tabular}

